\title{
Probable caso de reinfección grave por SARS-CoV-2 con coinfección por Legionella pneumophila
}

\section{Probable case of severe SARS-CoV-2 reinfection with Legionella pneumophila co-infection}

Rodrigo Cruz Choappa', Jeannette Dabanch² y Eduardo López²

${ }^{1}$ Centro de Diagnóstico e Investigación de Enfermedades Infecciosas (CDIEI). Universidad de Valparaíso. Instituto de Seguridad del Trabajador de Viña del Mar. ${ }^{2}$ Infectología, Universidad de Valparaíso.

Conflicto de intereses: los autores no tienen conflictos de intereses.

Financiamiento: Universidad de Valparaíso.

Recibido: 20 de enero de 2021 / Aceptado: 25 de mayo de 2021

\section{Resumen}

La inmunidad conferida luego de una primera infección por SARS-CoV-2 y el riesgo consiguiente de infección persistente o reinfección no están completamente dilucidados. Existen reportes internacionales de casos de reinfección, incluyendo el primer caso publicado en Sudamérica. Por otra parte, las comunicaciones de casos de coinfecciones han ido en aumento, incluyendo las asociadas a Legionella pneumophila. Presentamos el caso de un varón de 47 años de edad, personal de salud, que luego de cuatro meses de una primera infección por SARS-CoV-2, presenta una neumonía grave, certificándose una nueva infección por SARS-CoV-2 y una coinfección por L. pneumophila mediante detección de antígeno urinario. Fue tratado en UCI, requiriendo ventilación mecánica, dexametaxona y moxifloxacino, con buena respuesta clínica. Actualmente se encuentra en rehabilitación respiratoria y motora.

Palabras clave: COVID-19; reinfección; Legionella pneumophila; coinfección.

\section{Introducción}

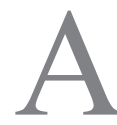
ún no existe consenso acerca de la duración de la inmunidad conferida luego de una primera infección por SARS-CoV-2 y del riesgo consiguiente de infección persistente o reinfección ${ }^{1,2}$. Ambos escenarios podrían tener implicaciones críticas para el manejo y control de la pandemia por COVID-19. Hasta el momento existen solo

\begin{abstract}
The immunity conferred after a first SARS-CoV-2 infection and the consequent risk of persistent infection or reinfection are not fully elucidated. There are reports both in Europe and in North America of reinfection cases, recently highlighting the first case published in South America. On the other hand, reports of co-infections have been increasing, including those associated with Legionella pneumophila. We present the case of a 47-year-old male, health personnel who, after four months of a first SARS-CoV-2 infection, suffers a severe pneumonia certifying a new SARS-CoV-2 infection and a L. pneumophila co-infection by urinary antigen detection. He was treated in the ICU, requiring mechanical ventilation, dexamethasone, and moxifloxacin, with a good response. He is currently in respiratory and motor rehabilitation.

Keywords: COVID-19; reinfection; Legionella pneumophila; coinfection.
\end{abstract}

reportes de casos de reinfección en Holanda, E.U.A ${ }^{1}$ y recientemente se ha publicado un caso en Sudamérica² .

El primer caso comunicado en el mundo de reinfección por SARSCoV-2 se documentó en agosto de 2020 en Hong Kong mediante la secuenciación genética de dos muestras recolectadas por hisopado nasal del mismo paciente con una diferencia de tiempo de 142 días. En este caso hubo evidencia de que los genomas virales pertenecían a linajes 
diferentes, uno de los cuales fue el que predominantemente circuló entre marzo y abril de 2020, mientras que el otro es el que predomina en la actualidad ${ }^{3}$.

Los reportes de coinfección con bacterias y hongos en pacientes con COVID-19 han ido en aumento desde el inicio de la pandemia ${ }^{4,5}$. Legionella pneumophila es un agente poco habitual que puede provocar neumonía grave, tanto en la comunidad como a nivel hospitalario, describiéndose algunos casos de coinfección con COVID-196,7.

Presentamos un caso probable de reinfección por SARS-CoV-2 con una coinfección por L. pneumophila.

\section{Caso clínico}

Varón de 47 años de edad, personal de salud, con antecedentes de hipertensión arterial en tratamiento con losartán $50 \mathrm{mg}$ al día, obesidad y tabaquismo crónico detenido hacía 8 años. El día 25 de julio de 2020 comenzó con un cuadro clínico caracterizado por fiebre hasta $38,5^{\circ} \mathrm{C}$, odinofagia, mialgias y tos escasa, confirmándose mediante TR-RPC una infección por SARS-CoV-2 (Cycle Threshold(CT): N1: 30,37; N2: 37,73; control endógeno: $21,50)$. No se pudo establecer un nexo epidemiológico en esta primera infección. Luego de estar en reposo por dos semanas y con tratamiento sintomático, se reintegró a sus labores clínicas sin mayores inconvenientes. A las cuatro semanas del diagnóstico se solicitaron títulos de IgM e IgG para SARS-CoV-2 por inmunofluorescencia (AFIAS-1, Boditech Med Inc.), los cuales fueron negativos. Luego de más de cuatro meses del primer episodio $\mathrm{y}$ de tener un contacto estrecho con otro funcionario de salud confirmado para COVID-19, el 1 de diciembre de 2020 presentó fiebre hasta $39^{\circ} \mathrm{C}$, mialgias, escalofríos, tos persistente y mayor compromiso del estado general, confirmándose con TR-RPC un nuevo episodio de infección por SARS-CoV-2 (CT: N1: 31,60; N2: 35,69; control endógeno: 22,47). Tres días después fue internado en la UCI del Instituto de Seguridad del Trabajador de Viña del Mar por una neumonía grave (Figura 1), iniciándose tratamiento con dexametasona i.v. $6 \mathrm{mg}$ día, ceftriaxona i.v. $1 \mathrm{~g}$ cada $12 \mathrm{~h}$. además de aporte de oxígeno por naricera. Por mayor requerimiento de oxígeno, disnea y polipnea se inició tratamiento con cánula nasal de alto flujo (CNAF) y pronación vigil, evolucionando inicialmente en forma favorable; sin embargo, al quinto día cursó con una mayor falla respiratoria, score de ROX que bajó de 14 a 5 y febril. Dentro de los exámenes hubo una aumento de la PCR: $351 \mathrm{mg} / 1$, recuento de leucocitos: 5.500 céls/ $\mathrm{mm}^{3}$, procalcitonina: $0,05 \mathrm{ng} / \mathrm{ml}$, dímero D: $10.000 \mathrm{ng} / \mathrm{ml}$, LDH: $261 \mathrm{U} / 1$. La radiografía de tórax mostró un extenso infiltrado intersticial con imágenes de consolidación mayor en el pulmón izquierdo (Figura 2).

Se conectó a ventilación mecánica invasora en posición prono y se inició noradrenalina por un shock asociado. En los hemocultivos no hubo desarrollo de bacterias y en panel molecular respiratorio (Filmarray $^{\mathrm{TM}}$, Biomerieux) no hubo identificación para otros virus (influenza A y B, parainfluenza, rinovirus, VRS, metapneumovirus y otros coronavirus), y bacterias atípicas (Mycoplasma, Chlamydophila o Bordetella). La detección de antígeno urinario para L. pneumophila por inmunocromatografía resultó positiva y para Streptococcus pneumoniae negativa, razón por la cual se inició tratamiento con moxifloxacino $400 \mathrm{mg}$ día. Tuvo una buena respuesta clínica, mejorando el intercambio gaseoso y bajando los requerimientos de oxígeno, volviéndose a supinar al tercer día de intubado. A los seis días de ventilación mecánica presentó un quiebre clínico con fiebre, aumento de los parámetros de actividad inflamatoria y aparición de imágenes consolidantes en ambos pulmones (Figura 3). Se agregó al tratamiento meropenem más vancomicina en espera de los hemocultivos y del cultivo cuantitativo de aspirado traqueal, los

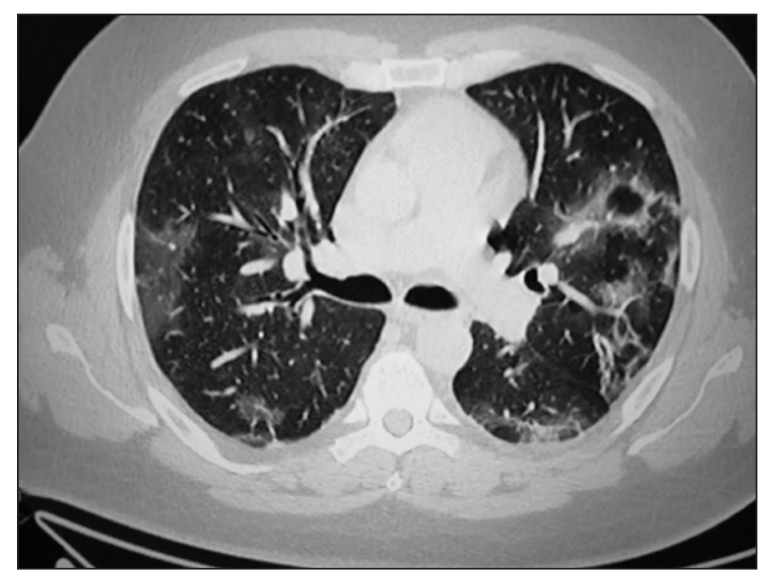

Figura 1. Extenso compromiso intersticial bilateral, con múltiples opacidades en vidrio esmerilado, además de opacidades lineales irregulares.

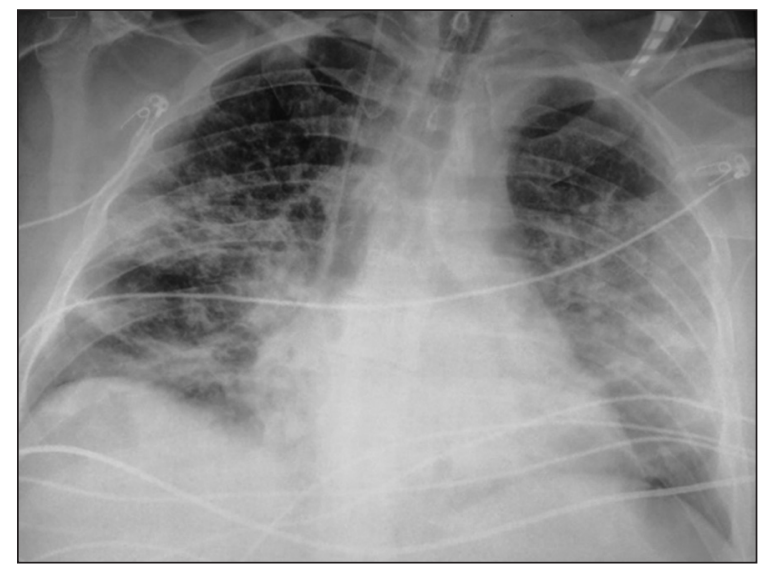

Figura 2. Radiografía de tórax con extenso infiltrado intersticial e imágenes de consolidación mayor en el pulmón izquierdo. 
Figura 3. Imágenes consolidantes basales, además de vidrio esmerilado bilateral.

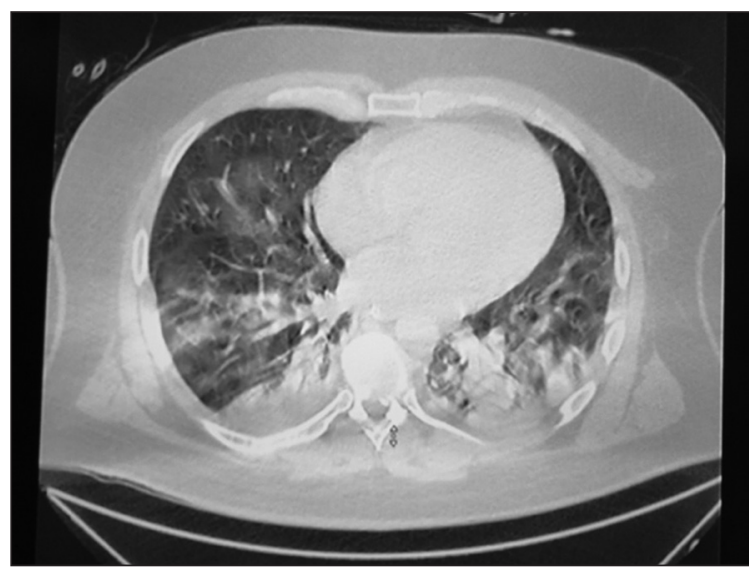

cuales resultaron negativos. Por persistencia de la fiebre y aparición de un rash, dermografismo y elevación de transaminasas se suspendió vancomicina. A los 13 días de ventilación mecánica se realizó un lavado broncoalveolar, encontrándose la mucosa bronquial eritematosa en forma difusa y con tapones mucosos en el lóbulo medio. Se tomaron muestras para cultivo cuantitativo bacteriano, panel respiratorio, RPC para Pneumocystis jirovecii, antígeno galactomanano, citomegalovirus y tinción de Gomori-Grocott, todos negativos. La prueba de ELISA de VIH y los marcadores reumatológicos también fueron negativos y el recuento de inmunoglobulinas fueron normales. Completó 14 días de moxifloxacino y meropenem. Los parámetros inflamatorios se normalizaron y la fiebre cedió. Del punto de vista respiratorio se realizó una traqueostomía sin incidentes, avanzando en el destete y retiro del ventilador mécanico.

Posteriormente, cursó con traqueobronquitis por $\mathrm{Pseu}$ domonas aeruginosa multisensible por lo que fue tratado con ceftazidima. Al momento de terminar este reporte se había retirado la cánula traqueal y se encontraba en rehabilitación respiratoria y motora, sin requerimientos de oxígeno.

A las cuatro semanas del diagnóstico del segundo episodio se le solicitaron títulos de IgM e IgG para SARSCoV-2 por inmunofluorescencia (AFIAS -1, Boditech Med Inc.), los cuales fueron negativos para IgM y de 81 COI para IgG.

\section{Diagnóstico molecular SARS-CoV-2}

La extracción de ácidos nucleicos se realizó utilizando el kit Omega Biotek MagBind Viral DNA / RNA 96 (Omega Bio-tek), según las especificaciones del fabricante. La TR-RPC en tiempo real se realizó por el ensayo multiplex 2019-nCoV Real-Time RT-qPCR Diagnostic Panel (CDC, E.E.U.U.) cargando alícuotas de $5 \mu \mathrm{l}$ de eluido.

\section{Diagnóstico de infección L. pneumophila}

Se utilizó la detección del antígeno en orina por inmunocromatografia con kit comercial Vitassay Healthcare, SLU. España.

\section{Discusión}

Se estima que $20 \%$ de los pacientes infectados con SARS-CoV-2 podrían no seroconvertir y desarrollar una nueva infección después de tres o cuatro meses ${ }^{8}$. Hasta el momento, la evidencia apoya que un segundo episodio de COVID-19 sería causado por una reinfección en lugar de una diseminación viral persistente, aunque hay un reciente reporte de este último escenario en un paciente intensamente inmunocomprometido ${ }^{9}$.

En este caso el diagnóstico de reinfección se planteó considerando los elementos epidemiológicos, clínicos, serológicos y una RPC para SARS-CoV-2 positiva luego de un primer cuadro de una infección resuelta. La evidencia de reinfección se ha documentado en base a la secuenciación de linajes distintos, después de la eliminación de una infección anterior ${ }^{10,11}$. Nuestro caso ocurrió en un individuo inmunocompetente, cuyo primer episodio demostrado de COVID-19 se presentó como una infección leve y sin evidencia de anticuerpos detectables a las cuatro semanas. Luego de más de cuatro meses asintomático, el paciente inició un nuevo cuadro clínico compatible confirmada con TR-RPC, pero esta vez con una infección grave $^{12}$. No se pudo realizar estudio molecular de linajes (secuenciación) para confirmar una reinfección o persistencia viral, debido a que no se contó con la muestra del primer episodio. La seroconversión de Ig total o de IgG, detectada por métodos de ELISA o inmunofluorescencia ocurre luego de la tercera o cuarta semana desde el inicio de los síntomas clínicos y constituye una evidencia de la respuesta inmune ante el COVID-19 ${ }^{13}$. Nuestro paciente no presentó títulos de IgG luego de la primera infección, lo que probablemente pudo haber favorecido un segundo episodio grave.

Aún no están completamente dilucidados los factores que influyen en una evolución clínica grave, proponiéndose que los determinantes parecen residir principalmente en el hospedero ${ }^{14}$, con evidencia discordante en relación al factor asociado al inóculo ${ }^{15}$. En los primeros dos casos reportados como reinfección se describió un cuadro clínico menos sintomático, sin embargo, en el caso en Ecuador, el segundo episodio tuvo una presentación francamente más grave. Esto es concordante con nuestro caso que cursó con un segundo episodio grave requiriendo manejo en UCI.

Desde el inicio de la pandemia por SARS-CoV-2 los reportes por coinfecciones han ido aumentando progresivamente y la coinfección con Legionella también se ha 
variante B.1.1.7 mostró una modesta disminución en la

descrito en pacientes susceptibles, con comorbilidades o inmunosupresión ${ }^{4,6,7}$. Legionella spp. es una bacteria transmitida por el agua (sistemas húmedos sin mantención), informándose brotes con mayor frecuencia en hoteles, centros de atención de larga estadía y hospitales. El diagnóstico se basa principalmente en la detección del antígeno en orina, con una especificidad cercana a $100 \%$ para el serotipo $1^{6}$. Nuestro paciente estuvo expuesto a aire acondicionado durante los meses previos a la infección; sin embargo, no había antecedentes de otras infecciones en el recinto hospitalario donde trabajaba.

Actualmente en el mundo, y también en nuestro país, nos enfrentamos a la emergencia de variantes de preocupación de SARS-CoV-2, cuyas características incluyen la evidencia de un aumento de la transmisibilidad, mayor gravedad de la enfermedad (aumento de hospitalizaciones o muertes), reducción significativa de la neutralización por anticuerpos posterior a la infección o vacunación y posibles fallas en la detección diagnóstica ${ }^{16}$. En estudios de muestras de suero de pacientes convalescientes, la actividad de neutralización, en un factor de 1,5 veces, mientras que la variante B.1.351 mostró un escape completo de los anticuerpos neutralizantes ${ }^{17}$. La secuenciación del ARN de SARS-CoV-2 es una herramienta fundamental para monitorizar la aparición y comportamiento epidémico de estas nuevas variantes, por lo que es un verdadero desafío implementarla en todas las regiones de nuestro país.

La exposición previa al SARS-CoV-2 podría no garantizar una inmunidad en todos los casos y si fuese así, no se sabe bien por cuanto tiempo. Lo anterior refuerza el hecho de que todas las personas, ya sean diagnosticadas previamente con COVID-19 o no, deben tomar las mismas precauciones para evitar la infección por SARS-CoV-2, debiéndose considerar el riesgo de reinfecciones, la emergencia de nuevas variantes y su implicancia en el desarrollo y la aplicación de vacunas. Por otra parte, debemos tener presente que existen las coinfecciones con otros agentes y que podrían agravar el cuadro clínico de COVID-19 y configurar un peor pronóstico.

\section{Referencias bibliográficas}

1.- $\quad$ Tillett R L, Sevinsky J R, Hartley P D, Kerwin H, Crawford N, Gorzalski A, et al. Genomic evidence for reinfection with SARS-CoV-2: a case study. Lancet Infect Dis. 2021; 21:52-8. doi: 10.1016/S1473-3099(20)30764-7.

2.- Prado-Vivar B, Becerra-Wong M, Guadalupe J J, Sully M, Gutierrez B, Rojas-Silva P, et al. COVID19 re-infection by a phylogenetically distinct SARS-CoV-2 variant, first confirmed event in South America. Disponible en SSRN 2020: http://dx.doi.org/10.2139/ssrn.3686174.

3.- Kai-Wang K, Fan-Ngai I, Daniel J, Wing-Ho A, Chan W, Raymond A, et al. COVID-19 re-infection by a phylogenetically distinct SARS-coronavirus-2 strain confirmed by whole genome sequencing. Clin Infect Dis. 2020; ciaa1275. doi: 10.1093/cid/ciaa1275.

4.- Dey R, Ashbolt N J. Legionella infection during and after the COVID-19 pandemic. ACS EST Water 2021; 1: 13-4. doi: 10.1021/ acsestwater.0c00151

5.- Bartoletti M, Pascale R, Cricca M, Rinaldi M, Maccaro A, Bussini L, et al. Epidemiology of invasive pulmonary aspergillosis among COVID-19 intubated patients: a prospective study. Clin Infect Dis. 2020; ciaa1065. doi: 10.1093/cid/ciaa1065.

6.- Arashiro T, Nakamura S, Asami T, Mikuni H, Fujiwara E, Sakamoto S, et al.
SARS-CoV-2 and Legionella co-infection in a person returning from a Nile cruise. J Travel Med. 2020; 27: taaa053. doi: 10.1093/jtm/ taaa053.

7.- $\quad$ Lai C C, Wang C Y, Hsueh P R. Co-infections among patients with COVID-19: The need for combination therapy with non-antiSARS-CoV-2 agents? J Microbiol Immunol Infect. 2020; 53: 505-12. doi: 10.1016/j. jmii.2020.05.013.

8.- Van Elslande J, Vermeersch P, Vandervoort $\mathrm{K}$, Wawina-Bokalanga T, Vanmechelen B, Wollants E, et al. Symptomatic Severe Acute Respiratory Syndrome Coronavirus 2 (SARSCoV-2) reinfection by a phylogenetically distinct strain. Clin Infect Dis. 2021: 73: 354-6. doi: 10.1093/cid/ciaa1330.

9.- Choi B, Choudhary M C, Regan J, Sparks J A, Padera R F, Qiu X, et al. Persistence and evolution of SARS-CoV-2 in an immunocompromised host. N Engl J Med. 2020; 383: 2291-3. doi: 10.1056/ NEJMc2031364.

10.- Torres D A, Ribeiro L D C B, Riello A P F L, Horovitz D D G, Pinto L F R, Croda J. Reinfection of COVID-19 after 3 months with a distinct and more aggressive clinical presentation: Case report. J Med Virol. 2021; 93: 1857-9. doi: 10.1002/jmv.26637.

11.- Centers for Disease Control and Prevention. Common Investigation Protocol for
Investigating Suspected SARS-CoV-2 Reinfection. Fecha de acceso: 03 de diciembre de 2010. Disponible en: https://www.cdc.gov/ coronavirus/2019-ncov/php/reinfection.html.

12.- Berlin D A, Gulick R M, Martinez F J. Severe COVID 19. N Engl J Med. 2020; 383: 2451-60. doi: 10.1056/NEJMcp2009575.

13.- Sethuraman N, Jeremiah S S, Ryo A. Interpreting diagnostic tests for SARS-CoV-2. JAMA 2020; 323: 2249-51. doi:10.1001/ jama.2020.8259.

14.- Kaser A. Genetic risk of severe Covid-19. N Engl J Med. 2020; 383: 1590-1. doi: 10.1056/ NEJMe2025501.

15.- Guallar M P, Meiriño R, Donat-Vargas C, Corral O, Jouvé N, Soriano V. Inoculum at the time of SARS-CoV-2 exposure and risk of disease severity. Int J Infect Dis. 2020; 97: 2902. doi: $10.1016 /$ j.ijid.2020.06.035.

16.- Centers for Disease Control and Prevention. SARS-CoV-2 Variant Classifications and Definitions. Fecha de acceso: 1 de mayo de 2020. Disponible https://www.cdc.gov/ coronavirus/2019-ncov/variants/variant-info. html

17.- Cele S, Gazy I, Jackson L, Hwa S-H, Tegally H, Lustig G, et al. Escape of SARSCoV-2 501Y.V2 variants from neutralization by convalescent plasma. Preprint at medRxiv. 2021. Disponible en: https://doi. org/10.1101/2021.01.26.2125022 4 . 